\title{
Characteristics of obstetric fistulas and the need for a prognostic classification system
}

Ates Karateke ${ }^{1}$, Cetin Cam ${ }^{1}$, Arman Ozdemir ${ }^{2}$, Buhara Guney ${ }^{1}$, Dogan Vatansever ${ }^{1}$, Cem Celik ${ }^{3}$

1Department of Pelvic Reconstructive Surgery, Zeynep Kamil Maternity Hospital, Istanbul, Turkey

2Department of Urology, Zeynep Kamil Maternity Hospital, Istanbul, Turkey

3Obstetrics and Gynecology Department, Namik Kemal University, Tekirdag, Turkey

Submitted: 5 January 2009

Accepted: 24 March 2009

Arch Med Sci 2010; 6, 2: 253-256

DOI: 10.5114/aoms.2010.13904

Copyright $\odot 2010$ Termedia \& Banach

\begin{abstract}
Introduction: To evaluate the need for a prognostic classification system for obstetric fistula (OF) with the data obtained by a voluntarily action for OF repair in a regional hospital and Niger, Africa.

Material and methods: Obstetric fistula (OF) characteristics of 51 women with vesicovaginal fistula in a fistula campaign in Maradi Regional Hospital, Niger were evaluated. Initial basic gynecological examination, methylene blue (MBT) test and direct cystoscopy were used to describe the characteristics of the lesions. Demographic and clinical data were compared with the existing literature.

Results: In $31(60 \%)$ cases were the sizes of the fistula greater than $4 \mathrm{~cm}$. The urethra was circumferentially lost in 8 (15.7\%) women. In 18 (35.3\%) women the trigone was involved. Extensive fibrosis was present in 10 (19.6\%) patients. Only in $11(21.6 \%)$ patients without any obliterating scarring, neither the trigone nor urethra were damaged. Five $(9.8 \%)$ patients had severe infection. Five $(9.8 \%)$ had multiple lesions. Thirty-four (66.6\%) had a history of at least one previous attempt for fistula repair. A significant proportion of women were divorced or abandoned from their husband, and socially isolated.

Conclusions: A simple, reproducible and universally accepted scientific classification or staging system for OF dealing with outcomes rather than anatomic landmarks should replace the present proposed classification systems for prognostic and ethical purposes.
\end{abstract}

Key words: obstetric fistula, classification system, surgical outcome.

\section{Introduction}

The association between vesicovaginal fistula and difficult labour was made more than 1000 years ago. Although the literature on this subject is extensive, anecdotal reports, small retrospective case series, and subjective views rather than facts still dominate the available data [1]. One of the most confusing aspects in the literature is the classification of these lesions, and there are more than 20 classification systems proposed for genitourinary fistulas [2]. Unfortunately, these classification systems are neither standardized nor associated with any prognostic factor or outcome measure.

Our intent was to report the characteristics of obstetric fistulas diagnosed by a voluntary action for fistula repair in a regional hospital in Niger, Africa and to evaluate the important risk factors for surgical outcome with some of the proposed classification systems.

\author{
Corresponding author: \\ Cem Celik \\ Namik Kemal University \\ Obstetrics and Gynecology \\ Department \\ Tekirdag, Turkey \\ E-mail: cemcel@yahoo.com
}




\section{Material and methods}

Obstetric fistula (OF) characteristics of 51 women with vesicovaginal fistula in a fistula campaign in Maradi Regional Hospital, Niger were evaluated. Initially, all patients underwent basic gynaecological examination. In women in whom the fistula tract could not be directly visualized on gynaecological examination, the methylene blue (MBT) test was performed via a Foley catheter inserted through the urethra, and extra-urethral leakage was explored either directly or with vaginal packs. Women with a positive methylene blue test (MBT) and no directly visible fistula tract underwent direct cystoscopy.

No patient had rectovaginal fistula and $66.6 \%$ had previous attempts at fistula repair. Operations were performed under spinal or epidural anaesthesia. The surgical team consisted of two urogynaecologists, one urologist, one anaesthesiologist and two residents of a urogynaecology clinic of a teaching hospital. Operations consisted of layered closure together with Martius fat or gracilis flaps, or

Table I. Demographic data of women

\begin{tabular}{|c|c|c|c|}
\hline $\begin{array}{l}\text { Age } \\
\text { [years] } \\
\text { mean } \pm \text { SD } \\
(\text { min-max })\end{array}$ & $\begin{array}{c}28.59 \pm 11.46 \\
(17-65)\end{array}$ & $\begin{array}{l}\text { Age at marriage } \\
\text { [years] } \\
\text { mean } \pm \text { SD } \\
\text { (min-max) }\end{array}$ & $\begin{array}{c}15 \pm 0.72 \\
(14-16)\end{array}$ \\
\hline $\begin{array}{l}\text { Gravidity } \\
(n) \\
\text { mean } \pm \mathrm{SD} \\
(\text { min-max })\end{array}$ & $\begin{array}{c}5.02 \pm 3.07 \\
(1-12)\end{array}$ & $\begin{array}{l}\text { Monthly income } \\
(\$) \\
\text { mean } \pm \text { SD } \\
(\text { min-max) }\end{array}$ & $\begin{array}{c}29.65 \pm 6.81 \\
(20-37.5)\end{array}$ \\
\hline $\begin{array}{l}\text { Parity } \\
(n) \\
\text { mean } \pm \mathrm{SD} \\
(\text { min-max })\end{array}$ & $\begin{array}{c}1.64 \pm 0.91 \\
(1-6)\end{array}$ & $\begin{array}{l}\text { Absent sexual } \\
\text { relations } \\
\% \\
\text { (n) }\end{array}$ & $\begin{array}{l}90.2 \\
(46)\end{array}$ \\
\hline $\begin{array}{l}\text { Duration of } \\
\text { incontinence } \\
\text { [months] } \\
\text { mean } \pm \text { SD } \\
\text { (min-max) }\end{array}$ & $\begin{array}{c}30.06 \pm 52.30 \\
(2-370)\end{array}$ & $\begin{array}{l}\text { Divorced } \\
\% \\
(n)\end{array}$ & $\begin{array}{l}47.1 \\
(24)\end{array}$ \\
\hline $\begin{array}{l}\text { Multiple } \\
\text { attempts } \\
\% \\
\text { (n) }\end{array}$ & $\begin{array}{l}66.6 \\
(34)\end{array}$ & $\begin{array}{l}\text { Abandoned } \\
\text { by husband } \\
\% \\
(n)\end{array}$ & $\begin{array}{l}43.1 \\
(22)\end{array}$ \\
\hline $\begin{array}{l}\text { Death of } \\
\text { the baby } \\
\% \\
\text { (n) }\end{array}$ & $\begin{array}{l}60.8 \\
(31)\end{array}$ & $\begin{array}{l}\text { Socially } \\
\text { isolated } \\
\% \\
(n)\end{array}$ & $\begin{array}{l}33.3 \\
(17)\end{array}$ \\
\hline $\begin{array}{l}\text { Operative } \\
\text { delivery } \\
\% \\
(n)\end{array}$ & $\begin{array}{l}35.3 \\
(18)\end{array}$ & & \\
\hline $\begin{array}{l}\text { Caesarean } \\
\text { section } \\
\% \\
(n)\end{array}$ & $\begin{array}{l}27.5 \\
(14)\end{array}$ & & \\
\hline
\end{tabular}

abdominal transvesical repair with an omental flap. Immediate postoperative outcomes were followed during the stay of the surgical team in the country for two weeks. Longer follow-up was impossible because no patient returned for the planned postoperative control 6 weeks after the operations.

\section{Results}

In 31 cases $(60 \%)$ the sizes of the fistula were greater than $4 \mathrm{~cm}$. The urethra was circumferentially lost in 8 women (15.7\%). In 18 women (35.3\%) the trigone was involved. Extensive fibrosis was present in 10 patients (19.6\%). Only in 11 patients (21.6\%) without any obliterating scarring was neither the trigone nor the urethra damaged. Five patients (9.8\%) had severe infection, 5 (9.8\%) had multiple lesions, 34 (66.6\%) had a history of at least 1 previous attempt at fistula repair. No woman had rectovaginal fistula. MBT and cystoscopy were performed in 18 and 11 patients respectively. The demographic data of women are presented in Table I.

\section{Discussion}

In contrast to iatrogenic fistulas (IFs) following a caesarean section or hysterectomy presenting with a small communication, small in size, and located above the vesical trigone and far from the urinary continence mechanism, OFs are caused by a broad injury resulting in extensive scarring and breakdown of the more severely affected areas, and involve the urogenital barrier [3]. latrogenic fistulass are often easily accessible with minimal scarring, whereas OFs need special skill to be repaired because they are rarely simple [4]. The complexity of the OF may be the reason for inadequate data on its distribution, because in the absence of a universally accepted classification, the degree of complexity reported for an OF will remain subjective.

In our series, the characteristics of the lesions fall into three main groups and these are schematized (not for classification purposes) in Figure 1. In the majority of women the defects involved the trigone and/or the urethra to various extent and one fifth of OFs presented as in Figure 1A. Involvement of the continence mechanism is a crucial point in OF repair, necessitating special skills in creating a neourethra, additional continence operations and even urinary diversion procedures which may have fatal consequences.

Of the 25 classification systems reviewed for genitourinary fistulas, 7 were reported to be the most recent and most cited systems [2]. Although considerably important factors such as - type, location, number, and size (length and width of the fistula); involvement of other organs; degree of vaginal scarring; attachment of the fistula to the 
pelvic wall; condition of the urethral sphincter and permeability of the internal orifice of the urethra; location of ureteral orifices and their relation to the edges of the fistula; and presence of complications such as a recto-vaginal fistula and inflammatory lesions of the pelvis, vagina, vulva, or peritoneum - are proposed for the creation of these classification systems, no data are available for their prognostic value.

The size of the fistula is reported to be an important factor for the classification of a fistula but this should be questioned because the repair of relatively smaller lesions damaging the continence mechanism may have high failure rates [5] and a fistula of a pinhole size may be a subtle sign of a broader underlying area of severely traumatized and scarred tissue resulting in a breakdown of the repair with a surface larger than originally estimated. In our series, $19.6 \%$ of lesions were under $4 \mathrm{~cm}$ but involving the continence mechanism partially or totally. Additionally the number of lesions is also very important because multiple fistulas may be an indicator of a broad field of injury with more than one central area [4].

Anecdotal experience shows that the degree of scarring and the status of the urethra may be more important predictors of outcome. The degree of scarring can be described as mild if minimal fibrosis is present and the fistula tract can be mobilized easily, as moderate if wide dissections are mandatory to mobilize the bladder, and as severe if extensive fibrosis reduces the bladder capacity significantly. With a simple score formulated to describe these parameters, it was possible to stratify the patients into two groups with less and twice the chance of a successful outcome respectively [6]. The degree of mobility or fixation of the bladder and urethrovesical junction against the pubic bone predicts the difficulty of the
Table II. Factors of a proposed surgical prognostic classification system in OF

\begin{tabular}{l}
\hline Urethral involvement: \\
- partial \\
- total \\
\hline Degree of scarring: \\
- mild \\
- moderate \\
- severe \\
\hline Mobility of the urethrovesical junction: \\
- well \\
\hline fixed to the bone \\
\hline Previous repair \\
\hline Vaginal stenosis
\end{tabular}

dissection and the likelihood of a successful surgical closure [4]. It is noteworthy that the fibrosis or scarring is not considered as a factor in the majority of the recently proposed classification systems.

The first repair of obstetric vesicovaginal fistulas affords the best success rate and a fistula with graver prognosis is created when repair fails. The number of previous repair attempts is reported to be an important factor for a successful surgical closure of OF [7]. Unfortunately only one of the most cited classifications includes previous repair as a special consideration.

A proper classification system should contain mainly prognostic factors rather than anatomical descriptions of the lesions. Terms such as simple or complex should not be used because they are very subjective and depend on the skill of the surgeon. The size of the fistula does not directly show prognostic significance but it may represent the involvement of areas which affect the prognosis. Factors which must be included in a surgical prognostic classification system are shown in Table II.
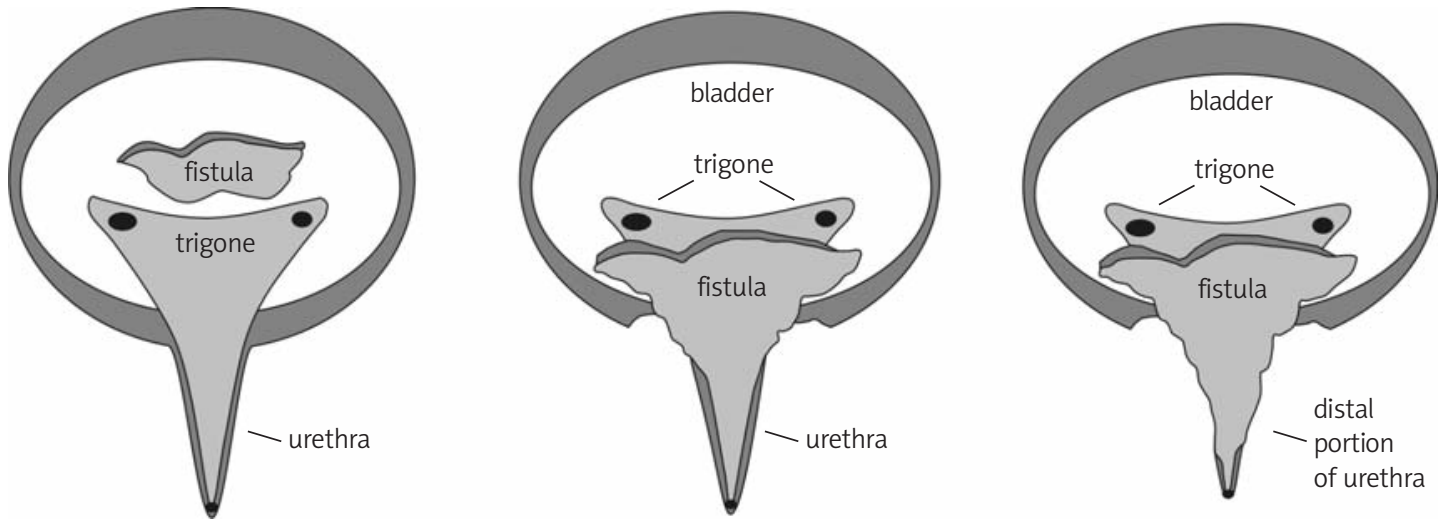

Figure 1. A - fistula not involving the trigone and urethra. B - fistula involving the trigone with minor defect at the urethra, $\mathrm{C}$ - fistula involving the trigone with major or total defect at the urethra 
Perhaps the most important aspect in the need of a classification system of prognostic value lies in the field of patient information. A surgeon who does not have any scientific evidence about the best surgical approach for any given OF cannot adequately inform the patient about the outcome and/or possible complications. These victims from impoverished rural backgrounds, waiting months or even years to be cured, are divorced or abandoned by their husband, socially isolated and depressed because of loss of their babies (Table I). In these regions of the world, diagnostic facilities are lacking and patients are often diagnosed very late in the course of their illness when irreversible changes and progressive deterioration have already occurred [8]. They may desperately give consent to undergo operations that they do not really understand, offered by surgeons who in fact do not have any reliable information about the outcomes of their approach. This is ethically unacceptable.

In conclusion, the proposed classification systems for OF are lacking in any prognostic data. A universally accepted scientific classification or staging system for OF should be simple, reproducible and dealing with outcomes rather than anatomical landmarks. Clinical risk factors and outcome measures collected from a standardized database should be the main factors considered. It should be able to help the surgeon to choose the best surgical approach and to inform his/her patient about the possible outcome of the planned procedure.

\section{References}

1. Hilton P. Vesico-vaginal fistulas in developing countries. Int J Gynecol Obstet 2003; 82: 285-95.

2. Creanga AA, Genadry RR. Obstetric fistulas: a clinical review. Int J Gynecol Obst 2007; 99: S40-6.

3. Wall LL, Karshima JA, Kirschner C, Arrowsmith SD. The obstetric vesicovaginal fistula: characteristics of 899 patients from Jos, Nigeria. Am J Obstet Gynecol 2004; 109 : 1011-6.

4. Genadry RR, Creanga AA. Roenneburg ML, Wheeless CR. Complex obstetric fistulas. Intl J Gynecol Obstet 2007; 99 (Suppl 1): S51-6.

5. Roenneburg ML, Genadry R, Wheeless Jr CR. Repair of obstetric vesicovaginal fistulas in Africa. Am J Obstet Gynecol 2006; 195: 1748-52.

6. Arrowsmith SD. The classification of obstetric vesico-vaginal fistulas A call for an evidence-based approach. Int J Gynecol Obstet 2007; 99 (Suppl 1): S25-7.

7. Kelly J. Vesicovaginal fistulae. Br J Urol 1979; 51: 208-10.

8. Belachew DA, Schaller BJ, Guta Z. Cervical spondylosis: a literature review with attention to the African population. Arch Med Sci 2007; 3: 315-22. 